\title{
Cued serial recall
}

\author{
DEWEY RUNDUS and JOHN R. FURINO \\ University of South Florida, Tampa, Florida 39620
}

\begin{abstract}
Three studies introduced cuing in a serial recall task by providing some items of a list being tested on the test sheet. Results indicated both enhancement and decrement of item recall for cued vs. noncued recall as a function of the serial positions of the items used as cues. Data are interpreted as inconsistent with position learning yypotheses, mildly supportive of item-item relationship hypotheses, and most consistent with tie Estes (1972) model of serial learning.
\end{abstract}

The search for the functional stimulus in serial learning has produced two general classes of explanations of learning in this paradigm. Beginning with Ebbinghaus (1885), numerous researchers have proposed that items of a serial list serve as stimuli for eliciting other list members; that is, serial learning consists of the formation of item-item connections. Alternatively, some theorists (e.g., Slamecka, 1964; Yntema \& Trask, 1963) have suggested that items of a serial list become associated with their position in the list and that positionitem, not item-item, relationships are the foundation of serial learning. Recent considerations of the possible hierarchical structure of memory have given rise to extensions of these two positions to more complex models of serial recall involving hierarchically structured item-item relationships (Estes, 1972) and hierarchically structured position-item associations (Johnson, 1972).

The experiments to be reported employed a cued recall procedure in an attempt to assess the extent to which item-item relationships were formed during serial learning. Specifically, on some recall trials in a serial recall task some of the items from the list were provided as cues on the subject's recall sheet. Recall of the nongiven items on these trials was compared with recall of items when no cues were provided. Explanations of serial recall which propose that item-item relationships are being formed during serial learning should predict differences in cued vs. noncued performance. Position theories should predict no effects.

Three similar experiments, employing some procedural modifications, were conducted. In the interest of brevity, Experiment 1 will be described and the procedural variations introduced in Experiments 2 and 3 will be indicated. Results of a combined analysis of the three studies, rather than individual experiment outcomes, will be reported.

A report of this research served as a thesis for the second author in partial fulfillment of requirements for an MA degree from the University of South Florida.

\section{METHOD}

\section{Subjects}

Thirty-two undergraduate female volunteers from an introductory psychology course were tested individually. Course credit was given for participation.

\section{Stimuli}

Four lists of 12 randomly selected moderate-frequency nouns (Thorndike and Lorge counts of 20-50 per million) were presented visually to each subject via a Kodak carousel slide projector.

\section{Procedure}

Each subject received three study-test serial recall trials on each of the four experimental lists. Items were presented for $1.5 \mathrm{sec}$ each with a blank slide inserted following Items 4 , 8 , and 12. The blank slides were intended to standardize the formation of sublist organizational units by subjects. Following exposure of the final blank slide, subjects were engaged in the overt distracting task of counting rapidly backward from 100 for $30 \mathrm{sec}$. A 1-min written serial recall followed the distracting task.

One manipulated variable was cuing. On a noncued recall test, the recall sheet contained only numbered lines for written recall. On a cued recall test, three items from the list being tested were written in their proper serial positions on the recall sheet. One cue item was selected from each of the three serial position blocks created by the blank slides. Each subject had both cued and noncued recall tests.

A second manipulated variable was trial of cuing. Three of the experimental lists were cued on one, and only one, of their recall trials. One of these lists had Trial 1 cued, one Trial 2, and one list was cued on Trial 3. The remaining list was never cued. Performance on each trial of this control list was used to assess the effects of cuing on the cued recall trials of the other lists. Each subject thus provided six data observations: noncued recall for each of the three trials of the control list and cued recall performance on the cued trial of the remaining three lists. The sequence of the four trial-of-cuing conditions was balanced across subjects.

The final manipulated variable was the serial positions from which the cue words were taken. This variable was manipulated between subjects. For one-fourth of the subjects the list items used as cues came from the first position in each of the induced four-item blocks (i.e., Items 1, 5, and 9). One-fourth of the subjects received cue items from the second position of each block (Items 2, 6, and 10), one-fourth from the third positions (Items 3, 7, 11) and one-fourth from the fourth positions (Items 4, 8, and 12). All recall scores were based only upon recall of items from noncued positions. Control list (noncued) 
recall was also scored only for items from positions which were not cued on the cued recall trials for a given subject.

Two study-test trials on a practice list were administered prior to the four experimental lists. The practice list was cued on the second trial.

\section{Procedural Differences}

Experiment 2 employed 64 subjects and new, but similar, word lists. Subjects were instructed to use the four-item blocks as organizational units and recall sheets used unnumbered lines. Experiment 3 used the instructions and recall sheets of Experiment 1 and the word lists of Experiment 2. Sixty-four subjects served in Experiment 3.

\section{RESULTS}

Analyses to be reported combined the data from Experiments 1, 2, and 3, treating experiment as an independent variable. The only significant effect of the experiment variable was an Experiment by Trials interaction in serial recall performance $[\mathrm{F}(4,244)=2.54$, $\mathrm{p}<.05]$. This interaction reflects a somewhat faster learning rate in Experiment 1. The lack of other effects of the experiment variable suggests that, while procedures and outcomes of the three experiments differed somewhat, the effects of the manipulated variables were similar in the three studies. A highly significant main effect of trials was observed in all analyses and will not be discussed. Two dependent variables were considered. For the first, serial recall, an item was scored as correct only if it was recalled in the correct serial position. The left three data columns of Table 1 present the probability of correct serial recall by trial and position of cuing for the noncued control list. The next three columns present the amount of enhancement (decrement) in recall observed on the cued recall trials [i.e., data in these columns show $P(R)$ cued minus $P(R)$ noncued for a given trial and position within a study block from which the cue items were drawn]. A reliable main effect of cuing was observed $[F(1,112)=9.43$, $p<.05]$, confirming a modest positive effect of cuing on serial recall. A Cuing by Trials interaction was also observed $[F(2,224)=4.06, p<.05]$, with subsequent tests indicating that a reliable cuing effect occurred only for Trial 1. Unfortunately, a possible confounding pre- vents clear interpretation of the serial recall data. On a cued recall trial the probability of correct serial placement, by chance, of a recall item is enhanced since the proper serial position of the three cue items is known. Since the extent of utilization of this position guessing is unknown, any form of correction would be arbitrary.

A second dependent variable, item recall, does not suffer from the above-mentioned confounding. For the item recall measure an item is scored as correctly recalled regardless of its position on the recall sheet. The second six columns of Table 1 present the probabilities of item recall for cued and noncued recall trials as a function of trial and cue word serial position. As before, the first three columns present noncued data and the final three columns present changes in recall due to cuing. For the item recall measure the main effect of cuing was not significant; however, a significant Position of Cue by Cuing interaction was observed $[\mathrm{F}(3,112)=$ $2.76, \mathrm{p}<.05]$. Subsequent tests indicated that the source of this interaction lay in a marginally significant facilitation of recall with Position 1 cues $[F(1,112)=$ 3.48 ] and a marginally significant negative effect of Position 4 cues on recall $[F(1,112)=3.84$, both $.05<\mathrm{p}<.10]$. A Cuing by Trials interaction was reliable $[\mathrm{F}(2,224)=4.24, \mathrm{p}<.05]$, with subsequent tests indicating a reliable effect of cuing only on Trial 1.

\section{DISCUSSION}

Because of the possible confounding in the serial recall measure, attention will be focused on the item recall analysis. The presence of a small, but reliable, effect of cuing on item recall is inconsistent with the position learning explanation of serial learning. Unfortunately, the magnitude of this effect is only somewhat supportive of the item-item relationship hypothesis. Of interest is the effect of cue position on cued recall. In particular, the negative effect of Position 4 cues is difficult to explain using only simple item-item links. The observed negative effect is reminiscent of the negative effect of providing list items as cues in free recall (e.g., Slamecka, 1968). The negative effect of cuing in free recall proved explicable when a hierarchical organization was considered (Rundus, 1973). This perhaps lends support for the Estes (1972) model of serial learning. Estes' model employs item-item relationships in a hierarchical structure, and thus is perhaps in the best position to account for the data observed in the three studies reported.

Table 1

Probabilities of Noncued Serial and Item Recall and Gain or Loss Due to Cuing for Combined Experimental Data

\begin{tabular}{|c|c|c|c|c|c|c|c|c|c|c|c|c|}
\hline \multirow{4}{*}{$\begin{array}{l}\text { Within } \\
\text { Block } \\
\text { Cue } \\
\text { Position }\end{array}$} & \multicolumn{6}{|c|}{ Serial Recall } & \multicolumn{6}{|c|}{ Item Recall } \\
\hline & \multicolumn{3}{|c|}{ Noncued Recall } & \multicolumn{3}{|c|}{ Gain (Loss) From Cuing } & \multicolumn{3}{|c|}{ Noncued Recall } & \multicolumn{3}{|c|}{ Gain (Loss) From Cuing } \\
\hline & \multicolumn{3}{|c|}{ Trial } & \multicolumn{3}{|c|}{ Trial } & \multicolumn{3}{|c|}{ Trial } & \multicolumn{3}{|c|}{ Trial } \\
\hline & 1 & 2 & 3 & 1 & 2 & 3 & 1 & 2 & 3 & 1 & 2 & 3 \\
\hline 1 & .28 & .66 & .83 & .10 & .06 & .06 & .37 & .73 & .89 & .06 & .03 & .02 \\
\hline 2 & $\begin{array}{l}.20 \\
.27\end{array}$ & .00 & .78 & .09 & .10 & .00 & .41 & .72 & .88 & .02 & .02 & $(.03)$ \\
\hline 3 & .32 & .68 & .84 & .08 & $(.02)$ & .02 & .40 & .76 & .89 & .09 & $(.04)$ & $(.01)$ \\
\hline 4 & .27 & .63 & .81 & .06 & $(.05)$ & .01 & .44 & .75 & .89 & $(.02)$ & $(.08)$ & (.01) \\
\hline
\end{tabular}




\section{REFERENCES}

Ebminghaus, H. On memory. Leipzig: Duncker \& Humblot, 1885.

Estes, W. K. An associative basis for coding and organization. In A. W. Melton \& E. Martin (Eds.), Coding processes in human memory. Washington, D.C: Winston, 1972.

Johnson, N. F. Organization and the concept of a memory code. In A. W. Melton \& E. Martin (Eds.), Coding processes in human memory. Washington, D.C: Winston, 1972.

Rundus. D. Negative effects of using list items as recall cues.
Journal of Verbal Learning and Verbal Behavior, 1973, 12, 43-50.

Slamecka, N. J. An inquiry into the doctrine of remote associations. Psychological Review, 1964, 71, 61-76.

Slamecka, N. J. An examination of trace storage in free recall. Journal of Experimental Psychology, 1968, 76, 504-513.

YNTEMA, D. B., \& Trask, F. P. Recall as a search process. Journal of Verbal Learning and Verbal Behavior, 1963, 2, 65-74.

(Received for publication May 9, 1977.) 